\title{
O SOFRIMENTO PSÍQUICO NA PERSPECTIVA DA PSICOPATOLOGIA FUNDAMENTAL
}

\author{
Paulo Ceccarelli*
}

\begin{abstract}
RESUMO. Partindo da palavra PSICOPATOLOGIA, o autor mostra, de forma resumida, como cada contexto histórico tentou "decompor" o sofrimento psíquico em seus elementos de base para classificá-lo, estudá-lo e tratá-lo. Após uma breve apresentação da psicopatologia na contemporaneidade, o autor introduz os pressupostos da Psicopatologia Fundamental e suas contribuições na compreensão do sofrimento psíquico. Ainda que não seja objetivo do texto participar do debate atual sobre as diretrizes curriculares que norteiam a formação do psicólogo, o autor toma o estudo do conhecimento (logos) da alma (psyché) - a psicologia - como exemplo de um dos campos de aplicação da Psicopatologia Fundamental.
\end{abstract}

Palavras-chave: psicopatologia, sofrimento, transdisciplinaridade.

\section{PSYCHIC SUFFERING FROM THE FUNDAMENTAL PSYCHOPATHOLOGY PERSPECTIVE}

\begin{abstract}
From the word PSYCHOPATHOLOGY the author briefly shows how each historical context had its own way to decompose psychic suffering in order to classify, study and search for its cure. After a short discussion about psychopathology in contemporaneity the author introduces the theoretical bases of Fundamental Psychopathology and its contributions to understanding psychic suffering. Although this text does not claim to participate in the debate about psychology students training, the author exemplifies through the study of the soul (psyche) knowledge (logos) one of the applications of Fundamental Psychopathology.
\end{abstract}

Key words: psychopathology, suffering, disciplinarian.

A palavra "Psico-pato-logia" é composta de três palavras gregas: "psychê", que produziu "psique", "psiquismo", "psíquico", "alma"; "pathos", que resultou em "paixão", "excesso", "passagem", "passividade", "sofrimento", "assujeitamento", "patológico" e "logos", que resultou em "lógica", "discurso", "narrativa", "conhecimento". Psico-patologia seria, então, um discurso, um saber, (logos) sobre a paixão, (pathos) da mente, da alma (psiquê). Ou seja, um discurso representativo a respeito do pathos psíquico; um discurso sobre o sofrimento psíquico $^{1}$; sobre o padecer psíquico. A psychê é alada; mas a direção que ela toma lhe é dada pelo pathos, pelas paixões.

Médico é aquele - diz Platão no Banquete - que está sempre atento ao pathos, às paixões, pois as doenças apresentam-se como um excesso de paixões. Como tal, cuida de Eros doente. Doente pelo excesso (pelo excesso pulsional). O médico é terapeuta, pois exerce a terapéia: o cuidado sobre Eros restabelecendo, assim, o equilíbrio pulsional para que Eros seja liberado desse excesso. $\mathrm{O}$ acometido pela paixão, o paciente, o passivo, o portador de sofrimento psíquico, é aquele que padece de algo cuja origem ele desconhece e que o leva a reagir, na maioria das vezes, de forma imprevista. As paixões atestam nossa permanente dependência ao Outro.

Cada contexto histórico-político teve sua psicopatologia, ou seja, suas tentativas de "decompor" o sofrimento psíquico em seus elementos de base para, a partir dai, compreendê-los, classificá-los, estudá-los e tratá-los. Como resultado, temos ao longo da história

* Psicólogo, psicanalista. Doutor em Psicopatologia Fundamental e Psicanálise pela Universidade de Paris VII. Docente da Graduação e Pós-Graduação do Departamento de Psicologia da Pontifícia Universidade Católica de Minas Gerais-PUC-MG.

1 A psicopatologia, como tradição, surge com os gregos, encontrando sua expressão máxima no teatro de Ésquilo (Berlinck, 1998; Fedida, 1992). 
várias metapsicologias, cada uma com referências próprias e diferentes perspectivas teórico-clínicas. Para Freud (Freud, 1976, p. 202), a "psicoanálise" é uma análise do psiquismo no sentido que a química dá a esse termo. Trata-se de decompor, de analisar, os elementos que constituem "os sintomas e as manifestações patológicas do paciente".

$\mathrm{Na}$ Grécia pré-socrática (Pessotti, 1995), o sofrimento psíquico era um castigo dos deuses irritados com a hybris dos homens. Em Homero, a Atê turva temporariamente a razão, fazendo da loucura um estado de desrazão. Por ser obra de Zeus, o homem não é responsável por sua loucura, e nenhum estigma é-lhe acarretado. A terapia era o misterioso pharmakon, que reinseria o sujeito em seu grupo social.

Nos textos trágicos, a loucura resulta da impossibilidade de escolha individual nos conflitos entre paixões, lealdades e deveres impostos pelo destino.

Nas obras de Eurípedes a loucura se psicologiza, e tanto a sua etiologia quanto os quadros clínicos são atribuídos às conseqüências das emoções na vida dos homens. O modelo mítico-teológico da antiguidade é substituído por uma visão racionalista das contradições, limitações e fraquezas humanas.

Com Hipócrates, a loucura - a perda da razão ou do controle emocional - é entendida como um efeito do desarranjo na natureza orgânica do homem. Sua etiologia deve ser buscada nas disfunções humorais. Tal concepção afasta definitivamente a influência divina na loucura. Essas idéias, que revelam uma visão organicista do distúrbio, terão profunda influência na medicina nos séculos XVIII e XIX.

Platão dá uma visão completamente nova da psyché, ao considerá-la como composta de três almas: uma racional, o logos, uma afetivo-espiritual e uma terceira que seria apetitiva. Para Platão, a loucura atestaria o desarranjo no equilíbrio das três componentes da psychê, fazendo com que a parte racional, o logos, perdesse o controle.

No segundo século da era Cristã, o célebre médico romano Cláudio Galeno retoma e aprimora a teoria platônica das três almas, apresentando uma concepção bem mais embasada da loucura. Entretanto, como Hipócrates, considera o desarranjo humoral como a causa da doença mental.

A visão medieval da loucura está intimamente associada, ou mesmo identificada, à possessão demoníaca. Esta perspectiva ganha espaço à medida que a hegemonia do cristianismo se impõe. Derivamse daí, por exemplo, as lutas contra os hereges que, por insistirem em cultuar divindades "pagãs", são vistos como encarnações do demônio (fenômeno extremante atual, quando os USA propõem-se lutar contra o "eixo do mal".)

Nos séculos XV e XVI o peso das explicações religiosas em relação à loucura começa a perder terreno, na medida em que o estudo da medicina, fortemente influenciado pelo retorno das idéias de Galeno, passa a considerar componentes psicológicas na loucura, o que propicia o aparecimento da noção de alienado.

Enquanto no século XVII as categorias platônicas são acrescentadas às teorias da loucura, o XVIII é marcado por uma psicopatologia desordenada, devido à falta de fundamentação sólida da fisiologia nervosa. Conseqüentemente a nosografia é difusa, com critérios variados e imprecisos. As classificações são ora extremamente abrangentes, o que as torna pouco úteis, ora drasticamente limitadas, tornando-se de difícil confirmação. No início do século XVIII o pensamento médico em relação às "doenças do espírito" e a prática do internamento permaneceram estranhos um ao outro; no final desse século as duas correntes pensamento e prática - sofrem uma primeira convergência, embora não se tratasse ainda de uma conscientização de que os internos eram doentes (Foucault, 1978, p. 432).

No início do século XIX, precisamente em 1801, Pinel publica seu Tratado Médico-Filosófico sobre a Alienação Mental. Obra revolucionária, o Tratado modifica radical e definitivamente a visão da loucura e inaugura uma nova especialidade médica, que mais tarde chamar-se-ia psiquiatria. É célebre o episódio, que se tornou histórico, de Pinel retirando os grilhões e correntes que prendiam os pacientes em Bicêtre. $\mathrm{Na}$ primeira edição do Tratado Pinel (Pinel, 2005, p. 72) escreve:

A alienação mental exige o trabalho atento de autênticos observadores para sanar a desordem em que se encontra.

E na segunda edição lemos (Pinel, 2005, p. 78):

Não se poderia compreender o conceito mesmo de alienação se não se enfoca a causa que mais freqüentemente a provoca, quero dizer, as paixões violentas ou exasperadas pelas contradições.

Esboça-se aqui o princípio que marcará a psiquiatria emergente: o apego à observação como procedimento para evitar as possíveis distorções no conhecimento da alienação provocada pela nebulosidade da psicopatologia vigente. 
Esquirol, o mais importante sucessor de Pinel, amplia os conceitos desse último ao sustentar que existem diversas formas de loucura, todas devendo ser compreendidas como distúrbios das funções racionais.

Até o final do século XIX não existia, em rigor, um saber sobre o sofrimento psíquico que acometia o homem. A preocupação vigente era a doença, a sintomatologia: conhecer para classificar. Os grandes psicopatólogos daquela época, dentre os quais Havellock-Ellis e Krafft-Ebing, tinham por preocupação classificar e etiquetar as organizações psíquicas que escapavam às referências de normalidade.

A expressão Psicopatologia, que deu nome ao que muitos médicos faziam, principalmente na França, na Alemanha e na Inglaterra, durante todo o século XIX, inaugurou a tradição médica que se manifesta, até hoje, nos tratados de psiquiatria e de psicopatologia médica. O aparecimento da Psicopatologia como disciplina organizada se dá com a publicação da Psicopatologia geral de Karl Jaspers, psiquiatra e filósofo, no início do século XX. Jaspers visava descrever e classificar, de forma minuciosa e sistemática, as doenças mentais.

A grande ruptura epistemológica é feita pela psicologia profunda de Freud. A partir da dimensão do desejo, que submetido às leis da linguagem escapa a qualquer apreensão direta de sua finalidade, Freud postula que o sujeito - louco ou não - sempre que fala, fala do, e a partir de,seu pathos, que aqui confunde-se com a trama discursiva que o constitui. É esta trama, inicialmente encarnada pelo Outro, que possibilita que o pathos, como passividade, alienação, transforme-se, na situação terapêutica, em percepção, em experiência.

Hoje, o termo "psicopatologia" encontra-se associado a um grande número de disciplinas que se interessam pelo sofrimento psíquico. Isso trouxe um problema, por vezes uma impossibilidade, tanto de diálogo intercientífico entre as diferentes abordagens teóricas, quanto de confrontação crítica dos modelos por elas utilizados, o que evidencia que o fenômeno psíquico não é redutível a uma única forma discursiva.

Dentre as inúmeras tentativas de superar os impasses criados pela pluralidade de leituras do pathos, o expoente máximo é, sem dúvida, o DSMIV (Manual de Diagnóstico e Estatística da Associação Psiquiátrica Americana) e o igualmente reputado CID-1O (Classificação Internacional de Doenças). Esses manuais oferecem uma definição empiropragmática das entidades nosográficas.
Busca-se, acima de tudo, "o ideal de um acordo mínimo com relação à delimitação formal e operacional das categorias diagnósticas empregadas" (Costa Pereira, 1998, p. 62). Tentouse criar uma nomenclatura única que forneça uma linguagem comum a pesquisadores e clínicos de diferentes orientações teóricas, uma abordagem feita unicamente a partir da observação direta dos fenômenos em questão; um sistema de classificação independente de qualquer apriorismo teórico. Isso significa deixar de lado os problemas etiológicos e centrar-se na nosografia. A grande crítica que se faz a esta abordagem é o fato de não levar em conta a subjetividade tanto daquele que está sendo "classificado" quanto daquele que classifica: o olhar de quem olha não é imune à sua própria organização subjetiva (é interessante lembrar que em julho de 2002, numa reunião realizada em Londres, Inglaterra, a Associação Mundial de Psiquiatria e a Organização Mundial da Saúde decretaram uma moratória de 10 anos para seus sistemas classificatórios - o DSM-IV e o CID-10 pois eles vinham sofrendo severas críticas, pois sua pretensão "universal" revelou-se inoperante).

Temos ainda o desenvolvimento das neurociências e o espantoso crescimento dos psicofármacos, que reforçam a idéia da origem biológica dos transtornos psíquicos. Podemos supor, sem exagero, que em breve não necessitaremos mais da psicopatologia para tratarmos um transtorno psíquico. Não será necessário levar em conta os aspectos subjetivos, os conflitos internos e as experiências psíquicas de cada um: bastará conhecer o uso das moléculas químicas (Ceccarelli, 2001).

Seja como for, os elementos da psicopatologia, as manifestações do pathos, constituem os princípios presentes nos estudos, pesquisas e tratamentos do psicopatológico, sejam eles feitos pela psiquiatria ou pela psicologia. Entretanto, por não haver uma rede significante única, uma trama discursiva última que acolha os elementos básicos da psicopatologia, o fenômeno patológico foi repartido em uma pluralidade de metapsicopatologias.

Torna-se, então, necessário que os pressupostos básicos da Psicopatologia sejam submetidos a interrogações sobre suas condições de possibilidade. Isto significa que devem ser objeto de uma ciência primeira, que o psicanalista francês Pierre Fédida (Berlinck, 1998) denomina Psicopatologia Fundamental: uma psicopatologia primeira, convocada a dar conta da interdisciplinaridade e da transdisciplinaridade presentes nas psicopatologias atuais. 


\section{PSICOPATOLOGIA FUNDAMENTAL}

A preocupação central da Psicopatologia Fundamental é contribuir para a redefinição do campo do psicopatológico. Ela propõe uma reflexão crítica dos modelos existentes e uma discussão dos paradigmas que afetam nossos objetos de pesquisa, nossas teorias e nossas práticas. A Psicopatologia Fundamental reconhece e dialoga com outras leituras presentes na polis psicopatológica.

A noção de fundamental deve ser compreendida no sentido de uma "fundamentalidade", uma "intercientificidade dos objetos conceituais". Trata-se de um projeto de natureza intercientífica, onde a comparação epistemológica dos modelos teóricoclínicos e de seu funcionamento propiciaria a ampliação do limite e da operacionalidade de cada um destes modelos e, conseqüentemente, uma transformação destes últimos. A Psicopatologia Fundamental é o fórum de toda a metapsicopatologia.

É importante frisar que não se trata de uma interdisciplinaridade, mas de uma transdisciplinaridade, pois campos diferentes, cada qual com métodos, procedimentos e objetivos próprios não se comunicam facilmente. A transdisciplinaridade reune, em uma ampla rede de significações, os conhecimentos específicos e singulares de cada modelo em torno de uma concepção ética comum aos diferentes saberes. Isso possibilitará a existência de um campo discursivo que produza interações e leve a construções metafóricas.

A Psicopatologia Fundamental, cujo campo conceitual é o da psicanálise, organiza-se em torno do patei mathos esquileano: aquilo que o sofrimento ensina. Trata-se de resgatar o pathos, como paixão, e escutar o sujeito que traz uma voz única a respeito de seu pathos, transformando aquilo que causa sofrimento em experiência, em ensinamento interno. Transformar o pathos em experiência significa, também, considerá-lo não apenas como um estado transitório, mas, - e talvez sobretudo - como "algo que alarga ou enriquece o pensamento" (Berlinck, 1998, p. 54). Cria-se um discurso sobre as paixões, sobre a passividade, sobre o sofrimento, enfim, sobre o sujeito trágico. Encontramos aqui a essência de Psicopatologia: o conhecimento da paixão, do sofrimento psíquico. O pathos, em si, nada ensina, não conduzindo senão à morte. Quando a experiência é, ao mesmo tempo, terapêutica e metapsicológica, estamos no âmbito da Psicopatologia Fundamental.

Por entender a questão páthica, as paixões, como uma dimensão inerente do Ser, a Psicopatologia
Fundamental sustenta que se crie uma psicopatologia própria a cada sujeito, que lhe permitirá transformar em experiência as manifestações de seu pathos; isto é, que lhe permita, via transferência, refazer seus caminhos pulsionais e suas escolhas objetais.

Embora a Psicopatologia Fundamental não dispense os saberes construídos por outros discursos para a compreensão do adoecer psíquico, ela não está tão interessada na descrição e classificação da doença mental, mesmo porque essa noção vem apresentando grandes transformações (Berlinck, 2003). Para a Psicopatologia Fundamental, o pathos manifesta uma subjetividade que é capaz, através da expressão em palavras, de transformar a paixão em experiência, servindo para a existência do próprio sujeito. $\mathrm{O}$ diagnóstico, para a Psicopatologia Fundamental, é apenas um recurso para orientar a escuta e balizar o caminho, e não um instrumento classificatórioideológico a ser utilizado para definir, a priori, uma organização ou uma estrutura na qual o sujeito deva ser encaixado; e menos ainda, um discurso que contribua para a cronificação do sofrimento e/ou discriminação do sujeito.

\section{PSICOPATOLOGIA FUNDAMENTAL E APARELHO PSÍQUICO}

A Psicopatologia Fundamental, no esteio das posições freudianas, concebe o psiquismo como uma organização que se desenvolveu para proteger o ser humano contra os ataques, internos e externos, que punham sua vida em perigo. O psiquismo é parte integrante do sistema imunológico: da mesma forma que um sujeito pode ser mais suscetível de contrair doenças por possuir um sistema de defesa debilitado, ele pode também estar menos equipado para responder aos ataques, internos (pulsionais, passionais) e externos (mudanças ambientais, perdas diversas), que encontra ao longo da vida e, por conseguinte, "adoecer" psiquicamente.

Essa concepção do psiquismo é tirada das teses apresentadas por Freud em um de seus textos mais polêmicos, cujas conseqüências ainda não foram totalmente avaliadas: Neuroses de transferência: uma sintese (Freud, 1987), Utilizando-se, mais uma vez, da referência mitológica, Freud concebe o aparelho psíquico (seelischer Apparat) como patológico em sua origem. Uma defesa contra o excesso; uma resposta à violência à qual o ser humano se viu exposto quando das mudanças provocadas por uma catástrofe ecológica de proporções avassaladoras: a perda do Éden. Para 
enfrentar o excesso sem adoecer - as transformações do meio ambiente (excesso externo) e as demandas pulsionais que não podiam ser satisfeitas (excesso interno) -, foram necessárias profundas reorganizações psíquicas. Esse longo processo, a História da Humanidade (filogênese) é repetida por cada ser humano (ontogênese). "As neuroses", escreve Freud (Freud, 1978, p. 72), "têm que prestar seu testemunho sobre a história do desenvolvimento da alma humana". O ser humano traz um sofrimento psíquico, geneticamente herdado, causado pelo excesso. Freud resgata a noção grega de pathos colocando-a como ingrediente central da essência do humano, de tal forma que a particularidade da organização psíquica de cada um deve ser compreendida como uma criação singular e única para garantir a sobrevivência da espécie. Para Freud, em Neuroses de transferência: uma síntese, as neuroses, as perversões e as psicoses são modos de subjetivação encontrados pelo sujeito frente à desmedida pulsional.

Se, por outro lado, o excesso (de pathos) causa dor, por outro, ele cria subjetividade. No humano, a dor tem um destino sui generis ao adquirir representação psíquica (Berlinck, 2000). É por "falar" que a dor solicita escuta; escuta essa que, sendo terapêutica, possibilita o recuo necessário para transformá-la em experiência. Na atualidade, entretanto, observa-se um movimento cada vez maior no sentido de eliminar a dor - de evitar contato consigo mesmo - do que para transformá-la em experiência. A espantosa produção de analgésicos, cada vez mais eficientes, revela "o desejo de se livrar da sensação, já que da dor o humano não se livra (Berlinck, 1999).

\section{PSICOPATOLOGIA FUNDAMENTAL E FORMAÇÃO DO PSICÓLOGO}

Embora não seja objetivo deste texto participar do debate atual sobre as diretrizes curriculares que norteiam a formação do psicólogo, tomaremos o estudo do conhecimento (logos) da alma (psyché), o da psicologia, como exemplo de um campo onde a Psicopatologia Fundamental teria uma palavra a dizer.

A psicologia, como ciência, foi construída ao longo da história como uma tentativa de compreensão de um fenômeno social novo. O "fenômeno novo" é o sentimento de "eu", cujas origens no Ocidente encontram-se na revolução burguesa, que transformou a organização feudal e instaurou uma nova forma de organização social. Isso significa que a psicologia surge como resposta a um movimento político historicamente datado, e que, como toda ciência emergente, é tributária da ideologia que permitiu o seu aparecimento. (Ceccarelli, 2002) Essa mesma ideologia apresenta distintas leituras do "fenômeno novo", do "eu", leituras essas que sustentam as diferentes epistemologias que definem tanto o normal como o patológico. Todo ensino de psicologia, em suas mais variadas áreas de atuação, apóia-se, ainda que implicitamente, em uma leitura do pathos. Essa, por sua vez, sustenta a epistemologia que define a noção de sujeito, a qual, conseqüentemente, determina a prática e orienta a clínica: psicopatologia clínica, psicopatologia do trabalho, das relações empresariais, do desenvolvimento...

Não obstante, a complexidade intrínseca do psicopatológico indica que o objeto de trabalho da psicologia - as paixões que constituem o sujeito não é apreensível por um discurso único e muito menos redutível a uma forma discursiva que o unifique. Daí a importância, na perspectiva de Psicopatologia Fundamental, de que o estudante de psicologia tenha contato com a multiplicidade das "psicopatologias" - fenomenológica, psicanalítica, existencialista, comportamental, humanista e outras tantas - para que ele se dê conta de que a psicopatologia que sustenta a prática psicológica constitui um vasto território habitado por diferentes perspectivas epistemológicas, com metodologias próprias e irredutíveis. Cada corrente teórica da psicologia propõe, dentro do referencial que lhe é próprio, possíveis apreensões do pathos que traduzem diferentes leituras do fenômeno observado - diferentes leituras do real - gerando diferentes construções da realidade.

A Psicopatologia Fundamental sugere que o estudo da psicopatologia no curso de psicologia deveria abordar os vários discursos sobre o pathos. Uma aula ideal convocaria psicopatólogos de diferentes filiações de maneira que, a partir de um determinado fenômeno psíquico, cada teoria da polis psicopatológica tivesse direito à palavra. Teríamos, neste caso, um exercício legítimo da transdisciplinaridade tal como a entende a Psicopatologia Fundamental: uma confrontação de modelos onde aquilo que pode parecer óbvio para um talvez seja motivo de perguntas para outro. Além disto, tal confrontação permitiria mostrar que 
tanto a nossa prática quando nossa escuta são determinadas pelo modelo que elegemos.

Um exemplo: tanto autores da Escola Inglesa (Khan, 1987; McDougall, 1972; 1997) quanto da Americana (Kernberg, 1975; 1998; Stoller, 1975; 1984) relatam casos clínicos de perversão trabalhados em análise com êxito. Para estes autores, a dificuldade com o perverso é suportar sua monotonia discursiva, o que requer do analista uma disposição particular para acompanhar o sujeito na repetição de sua pesquisa sexual infantil e, finalmente, introduzi-lo no mundo subjetivo de forma não ameaçadora. Já para a Escola Francesa de Jacques Lacan (Lacan, 1966; 1986), a perversão, vista como estrutura, resiste à psicanálise e o perverso não é analisável.

Ampliando a questão teríamos outro exemplo ainda mais radical: em agosto de 2004 ocorreu em Belo Horizonte o XIII Fórum Internacional de Psicanálise, organizado pelo Círculo Psicanalítico de Minas Gerais. O tema do Fórum foi "As múltiplas faces da perversão". Inspirado por ele, organizei na PUC-MG um debate sobre a perversão para o qual convidei colegas das diferentes linhas da psicologia. O resultado foi a total falta de consenso entre os debatedores sobre a definição de perversão, sua escuta e condução clínica. Ora, do ponto de vista epistemológico isso em nada nos surpreende, pois, como já disse, campos diferentes, cada qual com métodos, procedimentos e objetivos próprios dificilmente se comunicam. Mas para os alunos em formação o resultado foi angustiante. Ponderaram, e com razão, que para o sujeito que procura ajuda, sujeito esse que desconhece as correntes da psicologia, seu "futuro psíquico" estaria diretamente ligado à linha seguida pelo profissional que ele elegeu. Como resolver este impasse?

A pergunta que fica é: existe uma posição, uma leitura do fenômeno, mais verdadeira do que a outra, ou devemos nos perguntar sobre os limites da teoria que norteia nossa escuta? Ou ainda: existe um modelo mais verdadeiro que outro, ou é a nossa transferência que determina nossas escolhas teórico-clínicas? Questionar a certeza sobre a qual determinada enunciação repousa é o que caracteriza o discurso científico.

Muitas vezes, devido aos complexos inconscientes que são despertados em nós pela fala daquele que está em nossa frente, apressamo-nos a buscar respostas que confortem nossas angústias. Para evitar isso, devemos estar atentos às formas discursivas que apresentam respostas para tudo e, ao mesmo tempo, não suportam críticas: quando os conceitos teóricos transformam-se em dogmas, o discurso transforma-se em religião e seus pressupostos em leis. (Religião do latim "re-ligare" religar com Deus, ou com aquele que ditou, ou escreveu, a teoria.) Temos, neste caso, o dogmatismo, onde qualquer atividade crítica é severamente punida. Não podemos nos esquecer de que a dimensão imaginária da transferência pode transformar uma teoria em verdade incontestável.

É neste sentido - cabe repetir - que as diversas leituras do fenômeno psíquico devem ser reconhecidas como possíveis. Sem este reconhecimento, nossa prática corre o risco de transformar-se em uma prática perversa no sentido empregado por Freud nos 3 Ensaios: uma fixação de uma pulsão sexual em uma única forma de satisfação.

\section{REFERÊNCIAS}

Berlinck, M. (1998). O que é Psicopatologia Fundamental. Revista Latinoamericana de Psicopatologia Fundamental, 1(1), 46-59.

Berlinck, M. (1999). A dor. Revista Latinoamericana de Psicopatologia Fundamental, 2(3), 46-58.

Berlinck, M. (2000). Aspectos metapsicológicos das psicopatologias contemporâneas. Conferência apresentada em Fortaleza - CE em 13/05/2000, mas não publicada.

Berlinck, M. (2003). Ato Médico. Jornal do Conselho Federal de Psicologia. 28(75), 4-5.

Ceccarelli, P. R. (2001). Entrevista com Pierre Fédida. Revista Latinoamericana de Psicopatologia Fundamental, 4(1), 168174.

Ceccarelli, P. R. (2002). Psicologia Hospitalar: aspectos legais, éticos e políticos. Revista de Psicologia Plural, 17, 71-78.

Costa Pereira, M. (1998). Formulando uma psicopatologia fundamental. Revista Latinoamericana de Psicopatologia Fundamental, 1(1), 60-76.

Fedida, P. (1992). Tradition tragique du psychopathologique. A propos du pathei mathos de l'Agamemmon. Em Crise e contretransfert, Paris, PUF, 1992, 19-36.

Foucault, M. (1978). História da Loucura. São Paulo: Editora Perspectiva. (Trabalho original publicado em 1972).

Freud, S. (1976). Linhas de progresso na teoria psicanalítica. E. S.B., Vol. XVII, Rio de Janeiro: Imago. (Trabalho original publicado em 1918).

Freud, S. (1987). Neurose de transferência: uma síntese. Rio de Janeiro: Imago. (Trabalho original publicado em 1928).

Kernberg, O. F. (1975). Agressão nos transtornos de personalidade e nas perversões. Porto Alegre: Artes Médicas.

Kernberg, O. F. (1998). Perversão, perversidade e normalidade: diagnóstico e considerações terapêuticas. Revista Brasileira de Psicanálise, 32(1), 67-82. 
Khan, M. M. R. (1987). Alienación en las perversiones. Buenos Aires: Nueva Visión. (Trabalho original publicado em 1979).

Lacan, J. (1986). L'étique de la psychanalyse. (Lê séminaire liver 7). Paris: Seuil.

Lacan, J. (1966). Kant avec sade. Em Écrits. Paris: Seuil. (Trabalho original publicado em 1963).

McDougall, J. (1972). Scène primitive et scénario pervers. Em La sexualité perverse, Paris: Payot, pp. 50-94.

McDougall, J. (1997). As múltiplas faces de Eros: uma exploração psicanalítica da sexualidade humana. São Paulo: Martins Fontes.

Pessotti, I. (1995). A loucura e as épocas. Rio de Janeiro: Editora 34.
Pinel, P. (2005). Traité médico-philosophique sur l' aliénation mentale. Paris: Les empêcheurs de penser en ronds/Seuil. (Trabalho original publicado em 1809).

Stoller, R. (1975). Perversion. New York:Pantheon Books.

Stoller, R. (1984). La perversion et le désir de faire mal. In: Nouvelle Revue de Psychanalyse La chose sexuelle. 29, Paris: Gallimard, 147-172.

Recebido em 14/05/2005

Aceito em 30/09/2005
Endereço para correspondência:
Paulo Cecarelli, Rua Aimorés, 1239/702, Funcionários, CEP 30140-071, Belo Horizonte. E-mail:pr@ceccarelli.psc.br - Home page: www.ceccarelli.psc.br 